\title{
Unravelling the Challenges and Opportunities of Social Innovation across Market Boundaries through Images of Dress: An Abstract
}

\author{
Stephanie Slater and Catherine Demangeot
}

\begin{abstract}
This study explores the challenges and opportunities of social innovation in two multicultural societies, namely, France and the United Kingdom. We use the Cajaiba-Santana (2014) definition of social innovation to examine how the social innovation concept fits patterns reported in the context of multicultural societies following different acculturation modes. As pointed out by Cajaiba-Santana (2014), the social innovation literature is positioned around two lines of enquiry: institutional theory (DiMaggio and Powell 1983) which explains the role that institutions play in informing practice and structuration theory (Lettice and Parekh 2010; Giddens 1984), which explains the process of social action and evolution.

This study adopts an institutional perspective with a photo-elicitation methodology to capture consumer perceptions of modest dress and to identify, first, the role of the national context in shaping individual perceptions and, second, to capture the different institutional logics in action. We asked participants in both contexts (the United Kingdom and France) to share their conception of fashion in general and modest fashion in particular, via photo-elicitation. Whilst the intent of innovations in dress may not be social innovations, the way people use certain objects in different ways or understand certain changes differently may generate spillover effects (externalities) which do have implications for social value. Considering the "action and structure dichotomy", we capture the social motivation process of the different stakeholders.
\end{abstract}

References Available Upon Request

\author{
S. Slater $(\square)$ \\ Cardiff University, Cardiff, UK \\ e-mail: slaters@cf.ac.uk \\ C. Demangeot \\ IESEG School of Management, Paris, France \\ e-mail: c.demangeot@ieseg.fr
}

